\title{
3D CAD MODELING AND VISUALIZATION OF THE TUNNEL CONSTRUCTION PROCESS IN A DISTRIBUTED SIMULATION ENVIRONMENT
}

\author{
Yang Zhang \\ Elmira Moghani \\ Simaan M. AbouRizk \\ University of Alberta \\ Dept. of Civil \& Environmental Engineering \\ Edmonton, AB T6G 2W2, CANADA
}

\author{
Siri Fernando \\ City of Edmonton Asset Mgmt. and Public Works \\ Drainage Services, Design and Construction \\ Edmonton, AB T5J 3A3, CANADA
}

\begin{abstract}
Computer simulation has been successfully implemented in the construction industry for the decision making process; however, current modeling approaches focus mainly on process modeling and cannot integrate or assimilate information from different software. For a more complex project, 3D CAD models will help decision makers to improve integrity between design and construction process simulation, and process visualization will help them to detect deficiencies during the construction phase. High Level Architecture-based distributed simulation as a new simulation technique in construction facilitates integration and collaboration among various simulation models and allows us to standardize the integration process for computer software. It therefore enables us to integrate CAD models and 3D animation to visually control as-planned and as-built information. This paper proposes a methodology to integrate 3D modeling and visualization techniques with the tunneling construction simulation. The feasibility of the proposed methodology is validated in a real-life tunnel project in Edmonton, Alberta, Canada.
\end{abstract}

\section{INTRODUCTION}

Construction operations simulation has been shown to be an effective methodology for experimenting with different construction planning scenarios and considering various kinds of uncertainties of construction processes. It can help a project manager to forecast potential problems, arrive at an optimized solution, and finally achieve a successful project goal. Many software tools have been developed, including CYCLONE (Halpin 1977), STROBOSCOPE (Martinez 1996), Simphony (AbouRizk and Mohammad 2000), and so forth. However, the use of simulation in construction practices has generally been random and sporadic, falling far below its maximum potential (Halpin 1998). Ease of use is one important reason for the gap between research and application. Traditionally the outputs of a simulation run are presented in statistical tables and charts, which are not as easy to understand as a 3D model in a virtual reality world. Kamat and Martinez (2001) indicated that visualization of simulated operations in 3D can greatly help in establishing the credibility of simulation models and provide valuable insight into the subtleties of construction operations that are otherwise non-quantifiable and -presentable. The 3D visualization of specialpurpose simulation operations allows construction managers to construct simulation models and analyze results for themselves (Al-Hussein et al. 2006).

As part of ongoing research in distributed tunneling simulation (AbouRizk 2010), we take tunnel construction, which is an infrastructure project including many sophisticated tasks (Marzok et al. 2008), as a starting point to study and develop 3D modeling and visualization methodology to enhance the ease-ofuse of operation simulation in practice. To apply 3D visualization technology in tunnel simulation, we need to 1) create 3D models of as-planned pipeline, equipment, geology objects, etc., 2) develop a 3D 


\section{Moghani, Zhang, AbouRizk, and Fernando}

tunnel animation engine involving selection of a graphics API (application programming interface), importing graphics data, coding the rendering algorithm, dealing with user interaction, etc., and 3) establish a framework to enable different components to communicate with each other and maintain reusability in a distributed simulation environment.

The remainder of this paper is organized as follows: First, we review previous research related to 3D modeling and visualization in simulation. Then, we briefly introduce High Level Architecture (HLA), a distributed simulation standard, and the Construction Synthetic Environment (COSYE), an implementation of that standard. In the following sections, a tunnel information modeling system is proposed to integrate the tunnel geometry model and its related attributes with geology information. In the next section, the design and implementation of the 3D tunnel animation engine is discussed in detail. In order to validate the 3D modeling and visualization methodology, we take the North Edmonton Sanitary Trunk (NEST) project in Edmonton, Alberta, Canada, as an example. Finally, our contributions, the potential limitations of this approach, and future enhancements of the present research are discussed.

\section{LITERATURE REVIEW}

\subsection{Integration of 3D modeling with simulation}

Traditionally, Computer-Aided Design (CAD) was mainly used for drafting purposes or a reference for construction work at the job site. However, due to the recent demand for integrating design and construction information in the architecture, engineering and construction (AEC) industries, researchers have tried to integrate CAD models with other management tools by developing product models (Eastman 1999) which is a conceptual structure that contains all the details or information related to final product used to organize and communicate building product information among project participants (Howard 1989).

This integration facilitates the data transfer process from design documents to other construction management tools such as scheduling or cost estimating software. It helps a manager to visually control a construction progress, eliminates re-entry of data for every design changes or from one software to the other, and help in quality control process.

Construction simulation as a management tool can achieve the same benefits of this integration. During last two decades, several simulation tools were developed to assist project managers in decision making process, but are barely used in the industry, perhaps due to managers' preference for more tangible results rather than just statistical data or graphs. It is also inconvenient for them to do multiple re-entries of data when changes happen. 3D CAD models can carry other information rather than just geometry, which can be helpful for developing more accurate simulation models (Xu and AbouRizk 1999). Accordingly, integrating 3D CAD models with discrete event simulation has been proposed by different researchers to simplify simulation use (Kamat and Martinez 2001, Xu et al. 1999, AbouRizk and Mather 2000).

\subsection{Simulation Animation}

To improve the presentation of simulation outputs, 2D or 3D animations have been developed with different methodologies and technologies. Zhang et al. (2002) developed a 2D iconic animation for activitybased construction simulation, which can be used as a tool to verify a simulation model and to validate the obtained simulation results. Kamat (2003) developed a generic visualization tool called VITASCOPE, which uses a time trace file (a text file with predefined structure and syntax) to track simulation outputs from STROBOSCOPE and then generates 3D animation with the 3D model defined in VRML (Virtual Reality Modeling Language) format. An earthmoving case was presented by Kamat and Martinez (2001) to demonstrate VITASCOPE. Al-Hussein et al. (2006) and Manrique et al (2007) integrated 3D Studio Max with a special-purpose simulation system of crane operations (SimAnim) using MAXSCRIPT (a scripting language for 3D Studio Max). Lu et al. (2009) proposed a "zoom" interface between 4D CAD (Computer Aided Design) and 3D animation of operations simulation to integrate 4D presentation with simulation animation. 


\section{Moghani, Zhang, AbouRizk, and Fernando}

There are several shortcomings of the above mentioned methodologies and implementations. First, because most current simulation systems are standalone systems, visualization components cannot be easily shared and reused. AbouRizk et al. (2009) indicated that current simulation techniques are only effective when the models can be limited in scope and are limited to single user, as original construction simulation frameworks were meant to tackle processes and operations rather than integrate projects within collaborative, multi-user environment. Second, there is no standardized data exchange method between visualization components and simulation engines, which makes communication between these components very difficult. Finally, most animation implementations are post-simulation animation, meaning animation can only be generated after the entire simulation model has been simulated. Post-simulation animation does not enable user interactivity with the simulation model during a simulation run and cannot provide important information to the simulation engine during the simulating period. Rekapalli et al. (2009) indicated that recent advances in computing power and an interest in using the technology for next generation applications now demanded accurate, high-speed, and concurrent animations, and proposed a scene graph update algorithm to support concurrent animation of simulation models.

\subsection{Distributed Simulation}

Construction simulation generally focuses on process modeling for decision making purposes in the planning stage; current techniques mostly simulate the construction process by showing different activities, required resources, and equipment without considering all project information including the project design or as-built product information. Available tools are developed based on the discrete event simulation method and cannot represent different modeling approaches or data forms in the same simulation model. As previously mentioned, the existing methods are single user applications and are not able to reflect the interactions between different participants in the simulation model (AbouRizk et al. 2009). Finally, most of the available models are not reusable for similar future projects, making them a one-time application tool.

Due to mentioned limitations, simulation of a complex project using current methods may result in an inefficient decision making tool or reduce the accuracy of the results. To simulate more complex projects and facilitate interactions of different parties in one simulation environment, a distributed simulation technology is introduced based on High Level Architecture (HLA) (AbouRizk 2006). Distributed simulation is an application of distributed system technology that breaks down a complex system into more manageable components and helps components to interoperate over a communication network (Boer et al. 2006), supporting both their flexibility and their reusability in future models. This technology also reduces execution time by dividing the simulation computation over different computers and allows the integration of different software and simulation techniques (discrete event, continuous and real time)(Fujimoto 2000).

The High Level Architecture (HLA) was developed by the United States Department of Defense to reduce the cost and effort of developing simulation models for military purposes. Using HLA standards, individual simulation components, called federates, can be created by different developers with various simulation techniques or tools while maintaining interoperability among them in a one complex system, called a federation. A federation needs a Run Time Interface (RTI) to control the data flow between federates, and a Federation Object Model (FOM), which contains the common object model for the data exchanged between federates in a federation (Kuhl et al. 1999). HLA has been used for modeling supplychain logistics (Boer, 2005), scheduling and productivity improvement (Taghaddos et al. 2008), and steel fabrication (Alvanchi et al. 2009; Azimi et al. 2009). 


\section{TUNNELING CONSTRUCTION SIMULATION}

\subsection{Architecture of the tunnel federation}

In this study, a distributed simulation model for tunnel construction was created using COSYE (Construction Synthetic Environment), an HLA-based simulation environment developed at University of Alberta (AbouRizk 2006). COSYE facilitates simulating complex projects by dividing them in smaller components (federates), involving different developers, and using various simulation techniques and computer software. It consists of three major components: the COSYE RTI Server, the Object Modeling Template (OMT) editor, and the COSYE Framework (AbouRizk and Hague 2009).

Creating the FOM, which defines the communication language between federates, is the first step in developing a federation. The FOM document is created in a C\# or Visual Basic project; all predefined object classes, interaction classes, and data types are added as specified in the Object Model Template Specification. The created FOM is presented in a hierarchical fashion using a tree-type interface (Figure 1) and can be edited during the development process.

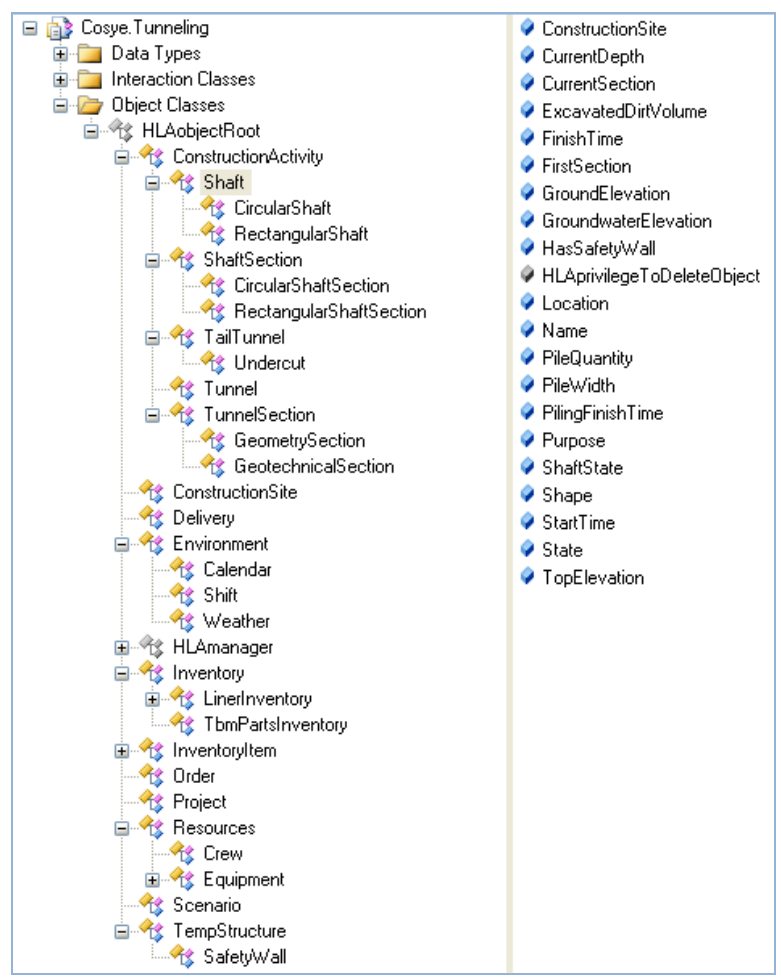

Figure 1: Tunnel Federation Object Model

The tunneling federation was then developed in Visual Studio 2008 using C\#. The federates are distributed such that each federate is responsible for simulating a particular construction process or specific activities in the project. This encourages "generic" federates which can be used for future projects; for example, the shaft federate just models the shaft construction, so a generic shaft model can be used in other projects that include shaft construction regardless of whether the shaft is a part of tunnel construction. The tunnel federation simulates the entire construction project consisting of the working shaft, tunnel and retrieval shaft construction, and supporting activities such as material supplies, weather, procurement, animation, etc. 


\subsection{Tunneling process and construction resources}

In urban areas, the tunnel boring machine (TBM) tunneling method is the most likely choice for tunnel construction.TBM tunnel construction consists of several typical phases, including preparatory tasks, working shaft construction, initial setup, tunnel construction, and removal shaft construction. In each phase, the as-planned infrastructure and construction resources have different working states, which are important to simulation modeling and 3D tunneling animation. Al-Bataineh (2008), Xie and Moghani (2009) provide more details of tunneling construction, but a summary is provided below:

- Preparatory tasks. Before the tunneling construction begins, there are a number of preparatory tasks, including ensuring availability of water supplies, electricity, easy access points, and space to store material on site.

- Working shaft construction. The working shaft is an access to the underground working area, where the TBM is installed, materials are delivered and dirt is removed from underground. For more working space, a tail tunnel is excavated at the tail of a working shaft.

- Initial setup. At the beginning of tunneling construction, the TBM and auxiliary machines and facilities (e.g. conveyor belt, trains and tracks) are set up and tuned to their working states.

- Tunnel construction. After the initial setup period, repetitive and sequential activities are conducted. As the TBM excavates and advances, the conveyor moves dirt to the train. After a certain distance, the TBM stops and installs lining in the tunnel. At the same time the train travels back to the working shaft, unloads dirt to the ground level and reloads lining materials. Then the train travels back to the TBM and the TBM starts the next section. There can be more than one train to save unloading and loading time and increase efficiency. During construction, the tunnel is surveyed to ensure it is advancing in the planned direction over a certain interval of time.

- Removal shaft construction. At the end of construction, a removal shaft is excavated, where machines are disassembled and moved to the ground level.

\section{TUNNEL INFORMATION MODELING SYSTEM (TIMS)}

In this project, the objective is to develop an integrated structure for tunneling construction simulation and as a part of this development, the integration of 3D CAD models with simulation is under investigation. All the geometry information and geotechnical data will be extracted from the 3D CAD model and entered as an input of the simulation. The 3D CAD model of the tunnel was developed based on available 2D CAD models developed in AutoCAD 2008.

\subsection{Architecture of Design Integration}

For integration purposes, a standard data exchange format is required; IFC, a common standard for building product models, does not provide all the required classes for the tunnel product model. So as a first step, a conceptual project model consisting of product, process, management, environment, and resource models for tunnel construction was developed. This model contains all the classes and attributes required for constructing a tunnel project. Figure 2 shows the conceptual project model for tunnel construction. 


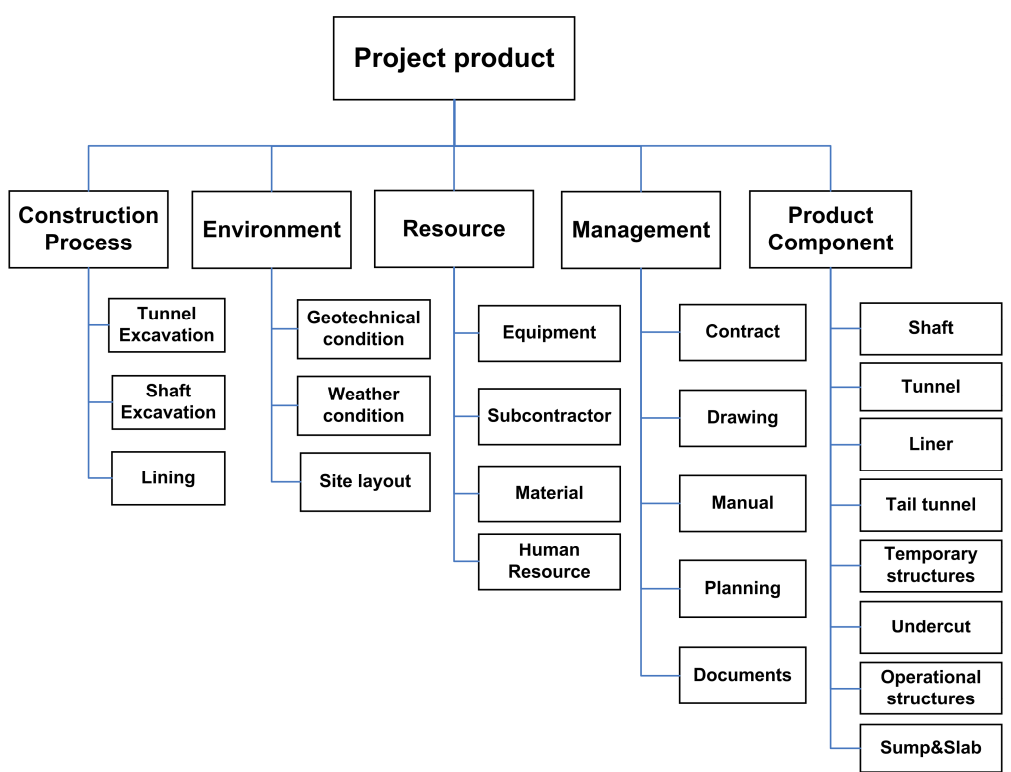

Figure 2: Tunnel Construction Project Model

HLA as a distributed simulation system facilitates the integration of planning, design, construction, and operation phases of construction projects; one major advantage is the common federation object model (FOM) that defines the data to be shared within the entire model. The conceptual model developed was used as a foundation for developing a comprehensive FOM. In this phase of the project, the objectbased 3D CAD model was developed in AutoCAD Civil 3D. One meter of a tunnel, called "tunnel section," was defined as a drawing block with related attributes such as soil type, chainage, diameter, and material type. An external database connects the 3D CAD model and the simulation model. The simulation model and 3D model will be updated based on actual data from the site. Figure 3 shows the integration and data transfer between the 3D CAD model and the simulation system.

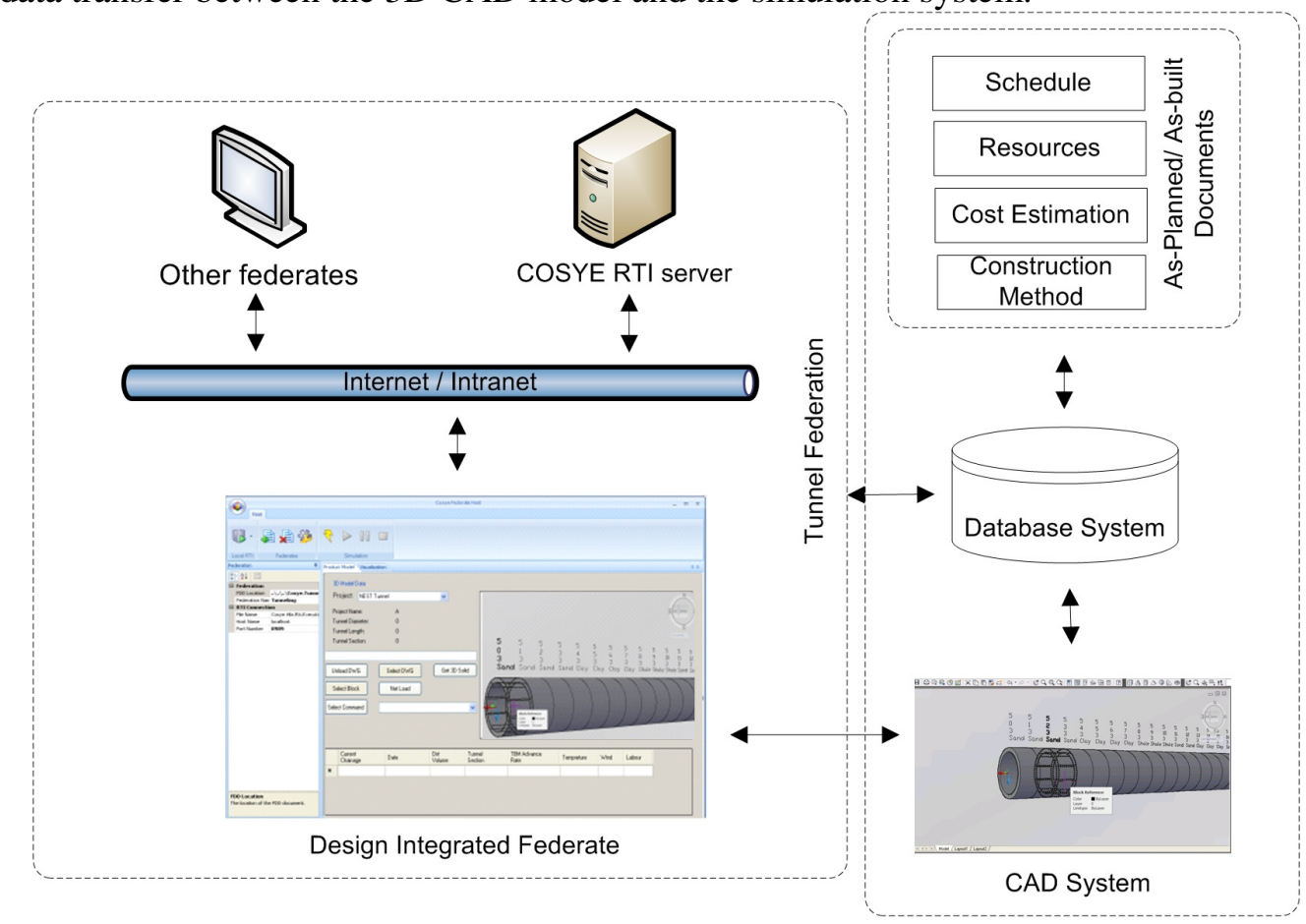

Figure 3: 3D CAD model and simulation integration 


\section{3D ANIMATION FEDERATE}

As a component of the tunnel federation, the 3D animation federate is designed to generate tunnel construction animation in a $3 \mathrm{D}$ environment according to the real-time simulation outputs from other federates. It receives and buffers the data defined in the FOM, and then displays smooth-motion 3D animation with a geology background. The $3 \mathrm{D}$ animation federate provides an realistic way to observe the construction activities undertaken.

\subsection{Design and Architecture of 3D Animation Federate}

The 3D animation federate consists of federate host, tunneling animation control, story board, graphic elements and graphic engine (Figure 4). The federate host is a generic component in COSYE. It receives and sends data to and from COSYE RTI server, and is where the tunneling animation control (TAC) is embedded. From the 3D animation point of view, the shaft and tunnel federates are two important federates which produce key frame data for animation. Information among these federates is shared with the object-oriented data model defined in the FOM with the Object Modeling Template (OMT) editor.

The TAC is a Windows ${ }^{\mathrm{TM}}$ control containing the animation logic code. To generate a smooth animation from discrete simulation outputs, this control linearly interpolates data between key frames recorded in the storyboard. Key frames correspond to the discrete events that take place in a simulation run. For example, when the TBM moves from location $l o c_{1}$ at time $t_{1}$ to location $l o c_{2}$ at time $t_{2}, l o c_{1}, l o c_{2}, t_{1}$ and $t_{2}$ are key frame data which are essential for animation generation. The movement of the TBM between $t_{1}$ and $t_{2}$ is assumed to be linear.

Graphic elements are drawable elements, including shaft, tunnel, TBM, train, borehole and ground profile, which are organized in an object-oriented paradigm and have their own position, state, private parameters and draw methods. As the simulation time advances, the TAC seeks key frame data by invoking proper methods in the storyboard, then updates the relating graphic elements. Then the graphic elements invoke their own draw methods to draw themselves on the computer screen. In this research, Microsoft $\mathrm{XNA}^{\mathrm{TM}}$ was chosen as the graphic API for 3D animation rendering. However, developers can choose any other graphic engines they like, due to the flexibility of the COSYE environment.

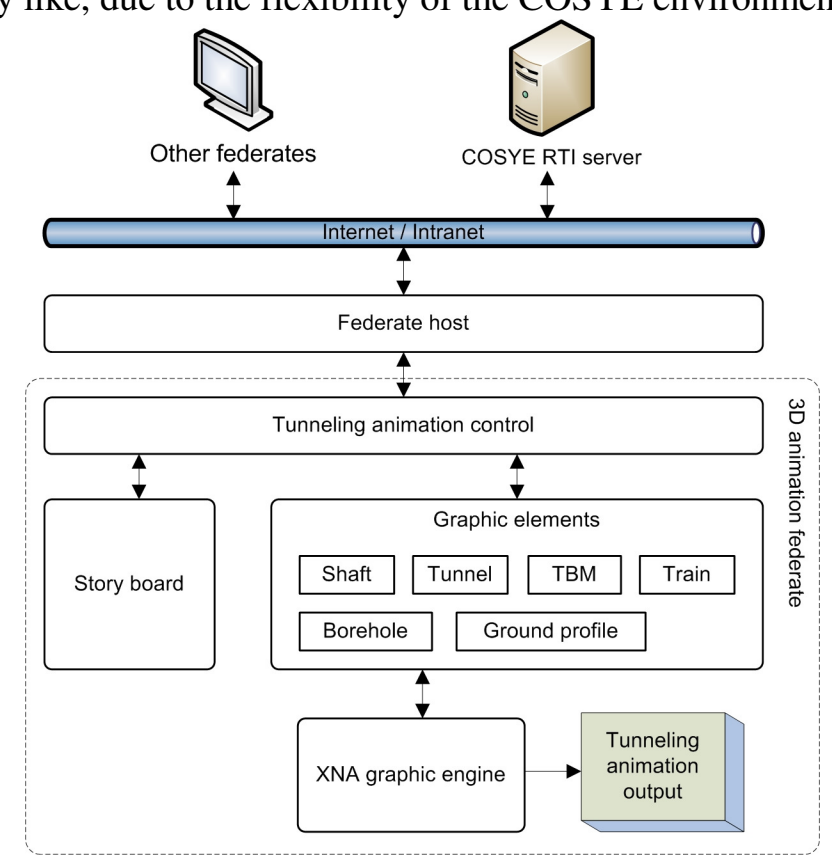

Figure 4: Architecture of 3D Animation Federate 


\section{CASE STUDY}

\subsection{Brief introduction to NEST}

As a case study, we developed a distributed simulation model for the North Edmonton Sanitary Trunk (NEST) project in Edmonton, Alberta, Canada. This $2.9 \mathrm{~m}$ diameter utility tunnel with a $3700 \mathrm{~m}$ length was excavated using a Tunnel Boring Machine (TBM). The project starts by excavating and lining a construction shaft in a sequential sections to get access to the tunnel depth. This shaft is used to access to the tunnel, remove excavated dirt and lower the TBM into the tunnel. The TBM excavates 1-meter sections, then puts concrete segments in place. This operation continues until the end of the tunnel. The retrieval shaft is constructed to remove the TBM at the end of the tunnel. At the bottom of the shafts, a larger area is excavated (tail tunnel and undercut) to facilitate TBM assembly and material handling process. The material handling is done using material carts and trains and a crane for vertical lifting.

\subsection{Simulation modeling}

Figure 6 shows a NEST tunnel federation, which contains 14 full functional federates. The federates and their descriptions are summarized in Table 1.

Table 1: Tunnel construction simulation federates

\begin{tabular}{|l|l|}
\hline \multicolumn{1}{|c|}{ Federate name } & \multicolumn{1}{|c|}{ Description } \\
\hline Scenario Setup & $\begin{array}{l}\text { User inputs such as shift length or project start date; project settings such as num- } \\
\text { ber of shafts or tunnels; and resource settings such as equipment and crew infor- } \\
\text { mation. }\end{array}$ \\
\hline Shaft & $\begin{array}{l}\text { Simulates the shaft construction process including preparation, excavation, and } \\
\text { lining }\end{array}$ \\
\hline Tunnel & $\begin{array}{l}\text { Simulates the complete process of constructing a tunnel including excavation, lin- } \\
\text { ing, resetting TBM, and TBM breakdown; it also covers other common activities, } \\
\text { like extending utilities and surveying }\end{array}$ \\
\hline Dirt Removal & $\begin{array}{l}\text { Simulates the process of removing dirt from the tunnel face to the undercut, } \\
\text { dumping dirt from undercut to ground, and loading carts with materials. }\end{array}$ \\
\hline Supplier & $\begin{array}{l}\text { Receives a new order from the contractor through the procurement federate, sche- } \\
\text { dules for delivery of a new order and sends a respond to the procurement federate. }\end{array}$ \\
\hline Procurement & $\begin{array}{l}\text { Tracks how many liners are in the inventory; if that level reaches a specific thre- } \\
\text { shold, the procurement federate places an order for the concrete lining segments } \\
\text { to the supplier. }\end{array}$ \\
\hline Bayesian Updating & $\begin{array}{l}\text { Applies a Bayesian updating method for predicting machine breakdown, TBM } \\
\text { advance rate, tunnel productivity, scheduling, and cost. }\end{array}$ \\
\hline Animation & $\begin{array}{l}\text { Displays a 2D and 3D animation of the construction process as the simulation is } \\
\text { running. }\end{array}$ \\
\hline Design Information & $\begin{array}{l}\text { Connecting a 3D CAD drawing to the simulation model, extracting as-planned } \\
\text { geometry and geotechnical information, and updating the as-built geometry }\end{array}$ \\
\hline As-built Information & $\begin{array}{l}\text { Capturing and storing all the as-built information based on data transfer from the } \\
\text { site. }\end{array}$ \\
\hline Emission federates & $\begin{array}{l}\text { Calculating energy consumption of the equipments and gas emission } \\
\text { A geographic federate which traces the TBM location on a map, providing a pa- } \\
\text { noramic view for project planners and engineers. }\end{array}$ \\
\hline Map & $\begin{array}{l}\text { Reports the project information and updated data regarding the advance rate of the } \\
\text { project. }\end{array}$ \\
\hline Project control &
\end{tabular}




\subsection{Design Information Federate}

Currently, the Design Information federate is able to connect 2D or 3D drawings to the simulation and extract different information such as block names, layers, and location of objects in a CAD model. The final goal is to have 2D/3D CAD drawings tagged with name, geometry, material and all the required attributes. The proposed approach will help to check the accuracy of the input data for process model simulation for quality control purposes.

This federate will remove the need for manual data entry, especially when new revisions of drawings are released. Uploading new drawings in this federate will update the simulation model with the latest data from the work site. Figure 5 shows an interface of this federate. The developed FOM in the COSYE environment is a comprehensive product model that will facilitate the integration process. The key advantage of the FOM in COSYE is its ability to expand according to further needs.

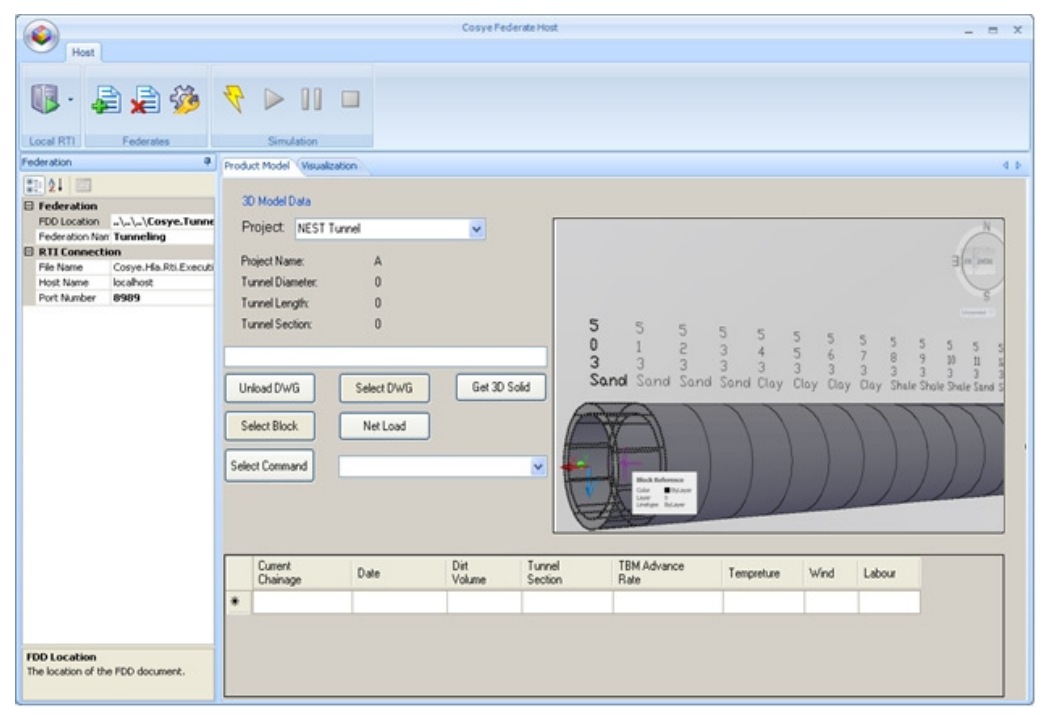

Figure 5: Design Information Federate

\subsection{D animation demo in NEST}

The 3D animation federate can demonstrate the tunneling construction process in a 3D environment (Figure 6). It can show different states of the TBM, for instance, excavating, lining, resetting, and waiting, as well as train travel to and from the tunnel face. The 3D models of TBM, train, shaft were developed in Autodesk ${ }^{\mathrm{TM}}{ } 3 \mathrm{ds} \mathrm{Max}^{\mathrm{TM}_{\circledast}} 2010$ and then converted to .x files, which can be loaded by the Microsoft XNA game engine. The animation speed (the ratio of game time to real time) can be adjusted by moving the slider bar on the top. More details of tunneling animation can be observed at a slower animation speed. Users can change the view point by panning via moving a mouse on the screen or with the arrow keys, or can directly input the parameters of the virtual camera. By selecting the camera tracing mode from the dropdown list at the bottom, the camera can be anchored on the TBM, anchored on the shaft, or set to work in free motion mode; an anchored camera will follow an object or area of interest (the TBM or the shaft), while in free motion mode the camera position can be controlled with the keyboard. 


\section{Moghani, Zhang, AbouRizk, and Fernando}

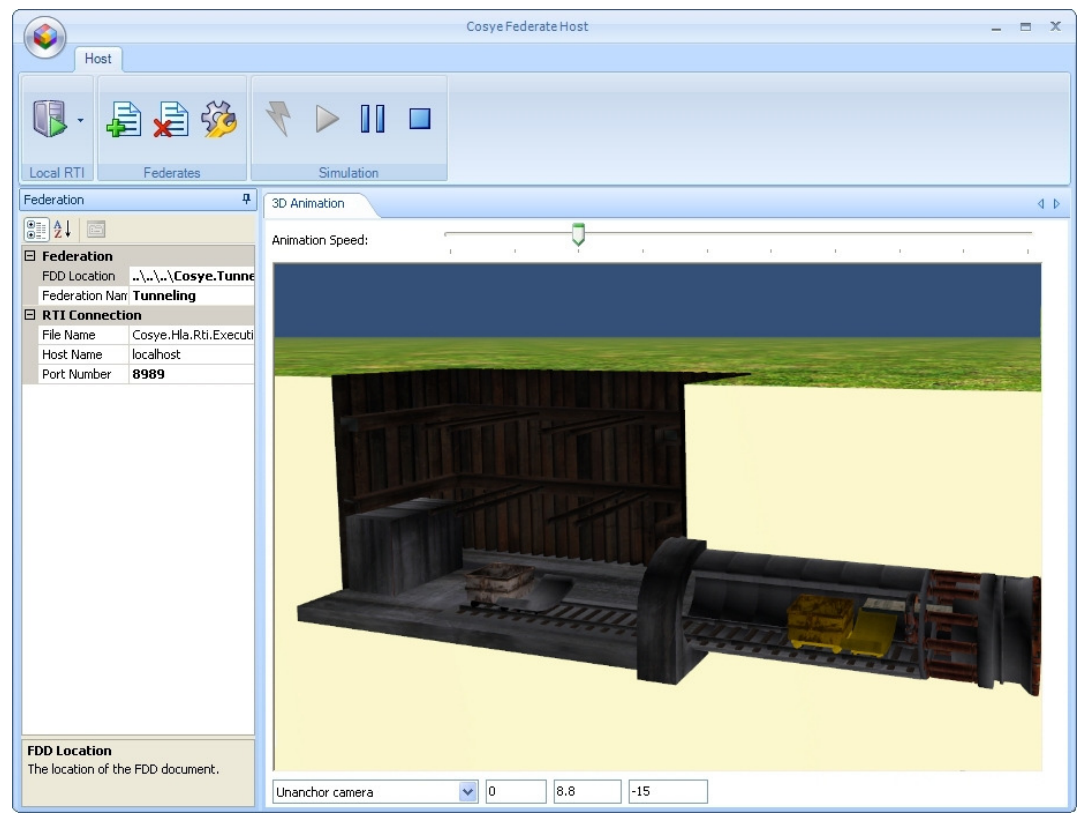

Figure 6: 3D animation of tunnel construction

\section{CONCLUSION}

This paper focuses on 3D modeling and visualization of tunnel construction. For complex projects with various kinds of uncertainties, the virtual 3D environment can help decision makers to increase the integrity between design and construction process simulation, and help them to detect deficiency during construction phase. A tunnel information modeling system is proposed to establish the tunnel information model, associate related attributes, and integrate geological strata data. A 3D tunnel animation federate is developed to present detailed tunnel construction processes, which provides an intuitive and effective way to inspect the simulation outputs. Different federates are integrated in the COSYE environment, an implementation of the HLA standard especially for construction simulation developed at the University of Alberta, to form a distributed tunnel simulation federation. These federates work together through the Internet or an intranet, sharing and exchanging data according to the FOM with the COSYE RTI server. Benefitting from the loose-coupled design, federates can be easily reused and work with other federates harmoniously. The feasibility of the proposed methodology is validated in a real-life tunnel project in Edmonton, Alberta, Canada. Future research will involve enhancing the 3D environment, so that not only can it generate 3D tunnel construction animation, it will also be capable of participating in the simulation process; for example, providing soil conditions from existed strata data to assist in forecasting the TBM penetration rate.

\section{ACKNOWLEDGEMENTS}

The authors gratefully acknowledge NSERC Industrial Research, Chair in Construction Engineering \& Management (Project \#335345-05 / N041000517), and the City of Edmonton for their kind collaboration. 


\section{REFERENCES}

AbouRizk, S. 2010. The role of simulation in construction engineering and management. J. Constr. Engrg. and Mgmt, ASCE. (In press)

AbouRizk, S. M., and Y. Mohammad. 2000. Simphony-An Integrated Environment for Construction Simulation. In Proceedings of the WSC 2000, Orlando, Florida, 1907-1914.

AbouRizk, S. M. 2006. Collaborative Simulation Framework for Multi-user Support in Construction. Discovery Grant Proposal.

AbouRizk, S. M., and S., Hague 2009. An overview of the COSYE Environment for Construction Simulation. In Proceedings of the 2009 Winter Simulation Conference, eds. M. D. Rossetti, R. R. Hill, B. Johansson, A. Dunkin and R. G. Ingalls, 2624 - 2634. Piscataway, New Jersey: Institute of Electrical and Electronics Engineers, Inc.

AbouRizk, S. M., S., Hague, M., Al-Bataineh, and S., Fernando. 2009. Collaborative Tunneling Simulation Using Synthetic Environments. In Proceedings of 2009 Construction Research Congress, Seattle, Washington, US, 1223-1232.

Al-Hussein, M., M. A., Niaz, H. T., Yu, and H., Kim. 2006. Integrating 3D Visualization and Simulation for Tower Crane Operations on Construction Sites. Automation in Construction 15: 554-562.

Alvanchi, A., S. H. Lee, and S. M. AbouRizk. 2009. Modeling Architecture for Hybrid System Dynamics and Discrete Event Simulation. In Proceedings of 2009 Construction Research Congress, Seattle, Washington, US, 1290-1299. Seattle, U.S.A.

Azimi, R., A. Alvanchi, S. Lee, and S. M. AbouRizk. 2009. Development of the Industrial Steel Construction Federation in the COSYE Environment. In Proceedings of Annual Canadian Construction Research Forum. Banff, Alberta, Canada.

Boer, C. A. 2005. Distributed Simulation in Industry. Doctoral dissertation. Erasmus University, Rotterdam, Netherlands.

Eastman, C. M. 1999. Building Product Models: Computer Environments supporting Design and Construction., CRC Press LLC, pp. 4-6

Fujimoto, R. M. 2000. Parallel and Distributed Simulation Systems. John Wiley \& Sons, Inc., New York.

Halpin, D. W. 1977. CYCLONE - method for modeling job site processes. Journal of Construction Division, ASCE, 103(3): 489-499.

Halpin, D. W. 1998. Construction simulation: a status report. In Proceedings of 5th Canadian Construction Research Forum, University of Alberta and Alberta Construction Industry, Alberta, Canada, 3341.

Howard, H. C., R. E. Levitt, B. C. Paulson, J. G. Pohl, and C.B. Tatum. 1989. Computer integration: reducing fragmentation in AEC industry. J. Comp. in Civ. Eng., ASCE, 3(1): 18-32.

Kamat, V. R. 2003. VITASCOPE: Extensible and Scalable 3D Visualization of Simulated Construction Operations. Doctoral dissertation, Department of Civil and Environmental Engineering, Virginia Tech, Blacksburg, VA.

Kamat, V. R. and J. C, Martinez. 2001. Visualizing simulated construction operations in 3D. J. Comp. in Civ. Engrg., ASCE, 15(4): 329-337.

Kuhl, F., Weatherly, R., and J. Dahmann. 1999. "Creating Computer Simulation System an Introduction to High Level Architecture”, Prentice-Hall Inc., Upper Saddle River, NJ, USA.

Lu, M., Y., Zhang, J. P., Zhang, Z. Z., Hu, and J. L., Li. 2009. Integration of four-dimensional computeraided design modeling and three-dimensional animation of operations simulation for visualizing construction of the main stadium for the Beijing 2008 Olympic games. Can. J. Civ. Eng., 36: 473-479.

Martinez, J. C. 1996. STROBOSCOPE: State and resource based simulation of construction processes. PhD Dissertation, University of Michigan, Ann Arbor, Michigan.

Marzok, M., M., Abdallah, and M., El-Said. 2008. Tunnel-sim: Decision support tool for planning tunnel construction using computer simulation. In Proceedings of Winter Simulation Conference, 2504-2511. 
Manrique, J. D., M., Al-Hussein, A., Telyas, and G., Funston. 2007. Constructing a complex precast titlup-panel structure utilizing an optimization model, 3D CAD, and Animation. Constr. Eng. Manage, 133(3): 199-207.

Rekapalli, P. V., J. C. Martinez, and V. R. Kamat. 2009. Algorithm for Accurate Three-Dimensional Scene Graph Updates in High-Speed Animations of Previously Simulated Construction Operations. $J$. Comput.-Aided Civ. Infrastruct. Eng., 24, 186-198.

Taghaddos, H., S. M. AbouRizk, Y. Mohamed, and I. Ourdev. 2008. Distributed Agent-Based Simulation of Construction Projects with HLA. In Proceedings of the WSC 2008,Miami, Florida, 2413-2420.

Xu, J., and S. AbouRizk. 1999. Product-Based model representation for integrating 3D CAD with computer simulation. Proceeding of the 1999 WSC, 971-977

Zhang, H., J. J., Shi, and C. M., Tam. 2002. Iconic Animation for Activity-based Construction Simulation. J. Comp. in Civ. Engrg., 16: 157-164.

\section{AUTHOR BIOGRAPHIES}

ELMIRA MOGHANI is a Ph.D. student at the Hole School of Construction in the Department of Civil and Environmental Engineering at the University of Alberta.

YANG ZHANG is a post doctoral fellow at the University of Alberta. He received a $\mathrm{PhD}$ degree in civil engineering from Tsinghua University in 2009. His research interests are in the area of construction management and construction information technology, including visualization, 4D-CAD, building information modeling and simulation animation. His email address is $<y a n g \cdot z$ hang@ualberta. ca $>$.

SIMAAN M. ABOURIZK holds an NSERC Senior Industrial Research Chair in Construction Engineering and Management at the Department of Civil and Environmental Engineering, University of Alberta, where he is a Professor in the Hole School of Construction. He received the ASCE Peurifoy Construction Research Award in 2008.

SIRI FERNANDO is Director of Design and Construction for the City of Edmonton Drainage Services and was elected a Fellow of the Canadian Society for Civil Engineers in 2009. 